\title{
Behavioral effects of postnatal lead acetate exposure in developing laboratory rats
}

\author{
CHARLES R. GEIST and BEN R. MATTES \\ University of Alaska, Fairbanks, Alaska 99701
}

\begin{abstract}
At 23 days of age, three groups of male albino Sprague-Dawley rats were exposed to lead at concentrations of 0,25 , or $50 \mathrm{ppm}$, provided ad lib, in the acetate form, for 35 days in the drinking water. When tested on the problems of the Hebb-Williams closed-field maze learning task, the subjects receiving both $50 \mathrm{ppm}$ lead acetate and $25 \mathrm{ppm}$ lead acetate displayed significantly impaired learning ability when compared to water-fed controls in the total number of error zones entered over the 12 test problems. The time taken to traverse the maze enclosure, however, was significantly reduced only in the group receiving $50 \mathrm{ppm}$ lead acetate. None of the overt manifestations characteristic of lead poisoning were observed. Learning deficits can be produced in the weanling rat at levels of exposure similar to those which cause encephalopathy in the developing neonate.
\end{abstract}

Investigations of the effects of lead exposure on the behavioral repertoire of postweanling and adult animals have, for the most part, shown an increased variability of performance with few significant effects in adult rats (Shapiro, Tritschler, \& Ulm, 1973) and sheep (VanGelder, Carlson, Smith, \& Buck, 1973). No learning impairments were found in rats on either avoidance or escape tasks (Brown, Dragann, \& Vogel, 1971) or in the modified Hebb-Williams maze (Snowdon, 1973), although Lanthorn and Isaacson (1978) report an exaggerated and heightened responsiveness, as well as reduced rates of spontaneous alternation. It has been hypothesized that the failure to discover learning impairments in animals exposed to lead in adolescence or adulthood is due to the maturation of the blood-brain and intestinal absorption mechanisms which prevent insult to the central nervous system (Lanthorn \& Isaacson, 1978; Snowdon, 1973).

Marked effects on behavior have been demonstrated in animals following exposure to inorganic lead during the prenatal or developing neonatal periods at dosages lower than those necessary to cause encephalopathy (Brown, 1975; Driscoll \& Stegner, 1976; Winneke, Brockhaus, \& Baltissen, 1977). Prenatal exposure to lead acetate or lead carbonate has been reported to significantly delay both eye opening (Reiter, Anderson, Laskey, \& Cahill, 1975; Snowdon, 1973) and the development of the righting reflex (Reiter et al., 1975). Hyperactivity and increased aggressiveness have also been found (Sauerhoff \& Michaelson, 1973; Silbergeld \& Goldberg, 1974; Winneke et al., 1977). That learning deficits occur in rats has been shown by Driscoll and Stegner (1976) in the slower acquisition of a visual discrimination task, by Snowdon (1973) in the performance in a modified Hebb-Williams maze, and by Winneke et al. (1977) in a difficult learning task, i.e., size discrimination, but not in an easy task, i.e., orientation discrimination. Although no effects on the performance of lambs in a modified Hebb-Williams maze have been demonstrated (Carson, VanGelder, Karas, \& Buck, 1974a), deficits were found in the acquisition of visual discrimination (Carson, VanGelder, Karas, \& Buck, 1974b). Preweaning exposure to lead in rats has shown similar learning impairments in terms of performance deficits in a $\mathrm{T}$-maze light-dark discrimination learning task (Brown, 1975) and in a two-way shuttle task (Sobotka, Brodie, \& Cook, 1975). No changes have been reported in either exploratory behavior (Brown, 1975) or spontaneous motor activity (Brown, 1975; Sobotka \& Cook, 1974). However, Allen, McWey, and Suomi (1974) found aggressiveness, decreased social exploration, hyperactivity, and increased clinging and vocalization in lead-exposed infant rhesus monkeys.

Of clinical interest is the problem of ascertaining safe environmental levels of lead for certain vulnerable segments of the population, such as pregnant women, infants, and children. In view of the findings that chronic, sublethal, exposure to inorganic lead imposed upon the developing animal might produce long-term behavioral alterations in the adult, the present study was designed to address the question of intoxication effects due to immediate presence of lead burden in soft tissue. The traditional HebbWilliams closed-field maze was selected, since it has been extensively employed for a variety of animal species (Rabinovitch \& Rosvold, 1951; Warren, 1961; Warren, Warren, \& Akert, 1961; Wells, Geist, \& Zimmermann, 1972; Wilson, Warren, \& Abbott, 1965; Zimmermann, 1969) and has been regarded as an intelligence test for animals (Hebb \& Williams, 1946). 


\section{METHOD}

\section{Subjects}

The subjects of this investigation consisted of 21 male weanling albino rats of the Sprague-Dawley strain obtained from King Animals Laboratories (Oregon, Wis.). All subjects were housed individually in standard stainless steel laboratory cages measuring $17.8 \times 24.5 \times 17.8 \mathrm{~cm}$. Purina Rodent Laboratory Chow 5001 (St. Louis, Mo.) and water, with or without lead acetate, were provided ad lib in the home cage. The animals were maintained on a 12 -h light/dark cycle commencing at 0800 . The laboratory temperature was maintained at $22.5^{\circ} \pm 2^{\circ} \mathrm{C}$, with moderate humidity.

\begin{abstract}
Apparatus
In order to assess the effects of postnatal lead acetate ingestion, a standard Hebb-Williams closed-field maze was employed. The individual problems and underlying principles were identical to those described by Rabinovitch and Rosvold (1951). The maze was constructed from .6-cm dressed lumber with specifications closely following those established by Rabinovitch and Rosvold (1951). The basic design of the maze was a $76.5 \times 76.5 \times 19.0 \mathrm{~cm}$ enclosure with start- and goalbox extensions, measuring 24.5 $\times 13.6 \times 19.0 \mathrm{~cm}$, located in opposite corners. The maze floor was divided into $3611.2-\mathrm{cm}$ squares routered into the floor of the enclosure. The squares served to aid in the placement of the barriers to form the individual problems and to identify error zones. Wooden barriers, $17.5 \times .6 \mathrm{~cm}$ with varying lengths, divided the enclosure to form the individual problems. The entire maze was painted gray.
\end{abstract}

\section{Procedure}

On arrival in the laboratory, the subjects were randomly assigned to one of three treatment groups: 0,25 , or $50 \mathrm{ppm}$ lead administered in the acetate form in the drinking water. The lead acetate was dissolved in deionized distilled water and provided ad lib from 23 days of age throughout the duration of the experiment. Testing in the Hebb-Williams closed-field maze began 35 days following the initial exposure to lead acetate in order to facilitate an accumulation of lead concentration to a steady-state level (Castellino \& Aloj, 1964). The initial body weights were recorded and taken on a weekly basis throughout the experiment.

At 53 days of age, all subjects began a 1-h/day feeding schedule. After 5 days, the subjects began pretraining in the barrierfree Hebb-Williams closed-field maze. At the end of each trial, the subjects were allowed to consume two 45-mg Noyes Precision Food Pellets (Lancaster, N.H.) located at the far end of the goalbox alley. Eight trials were given per day until each subject immediately traversed the maze enclosure and entered the goalbox. Following pretraining, 6 practice problems and 12 test problems were presented to each animal according to the method described by Zimmermann and Wells (1971). The subjects were presented with 1 practice problem each day and given eight trials. Following the practice problems, each subject was presented with 2 test problems per day with eight trials per problem for 6 days. On each test problem, the subject's score was the total number of error zones entered. Errors were scored each time a subject's two forefeet crossed into an error zone. If a cul-de-sac contained two error zones, two errors were scored when an animal crossed the second error line. However, when the animal left the cul-de-sac via the first error zone prior to crossing the second error line, only one error was scored. Repeated entries into an error zone were scored as errors. The positions of the error zones with reference to the problems have been described in detail (Rabinovitch \& Rosvold, 1951). Latency to leave the startbox, time to traverse the maze, and the number of squares traversed were recorded.

\section{RESULTS}

The effects of dietary lead acetate treatment on growth, expressed in terms of body weight, were determined by means of an analysis of variance. No significant differences in weight gain were found among the groups, as shown by mean body weights at the onset of the 1-h/day feeding schedule for the groups receiving 50,25 , and $0 \mathrm{ppm}$ lead acetate of $234.2,241.8$, and $232.8 \mathrm{~g}$, respectively $[\mathrm{F}(2,18)$ $=2.35, \mathrm{p}>.05]$.

Latency scores were transformed by computing the reciprocal of the time each subject spent in leaving the startbox for the maze interior and multiplying it by 100 . An analysis of variance of the transformed scores revealed no significant differences as a function of dietary lead concentration, although the animals receiving $25 \mathrm{ppm}$ lead acetate exhibited somewhat greater transformed mean latencies per trial $(\overline{\mathrm{X}}=$ 1.54) than either the animals receiving $50 \mathrm{ppm}$ lead acetate $(\overline{\mathrm{X}}=1.45)$ or the control animals $(\overline{\mathrm{X}}=$ 1.40) $[\mathrm{F}(2,18)=.72, \mathrm{p}>.05]$.

Maze times were transformed by computing the reciprocal of each measure times 100 , and an analysis of variance was performed to determine significant differences. The mean time spent in traversing the maze enclosure per trial for the groups receiving 50 , 25 , and $0 \mathrm{ppm}$ lead acetate was significantly different, as shown by mean transformed times of .27, .29 , and $.31 \mathrm{sec}$, respectively $[\mathrm{F}(2,18)=4.50, \mathrm{p}<.05]$. The subjects receiving $50 \mathrm{ppm}$ lead acetate were found to have traversed the maze significantly more slowly than the untreated control group $[\mathrm{t}(12)=3.18, \mathrm{p}<$ .01]. Significant differences in maze time were not found between either the subjects receiving $50 \mathrm{ppm}$ lead acetate and those receiving $25 \mathrm{ppm}$ lead acetate $[\mathrm{t}(12)=1.49, \mathrm{p}>.05]$ or between the subjects receiving $25 \mathrm{ppm}$ lead acetate and the control subjects $[t(12)=1.38, p>.05]$. All subjects, regardless of dietary condition, exhibited a significantly decreasing trend in the time taken to traverse the maze enclosure across trials, as evidenced by transformed trial means of $1.48,2.59,3.44,3.61,3.93$, $4.14,4.19$, and $4.57 \mathrm{sec}[\mathrm{F}(7,126)=122.15, \mathrm{p}<.001]$. Trend analysis of the trial means yielded significant linear $[\mathrm{F}(1,18)=534.87, \mathrm{p}<.001]$, quadratic $[\mathrm{F}(1,18)$ $=128.32, \mathrm{p}<.001]$, and cubic $[\mathrm{F}(1,18)=26.10$, $\mathrm{p}<.001$ ] components which accounted for $84.99 \%$, $11.14 \%$, and $3.47 \%$ of the total variance, respectively. No significant differences were found between the trends of the trial means for the three treatment groups in the linear $[\mathrm{F}(2,18)=1.13, \mathrm{p}>.05]$, quadratic $[\mathrm{F}(2,18)=1.15, \mathrm{p}>.05]$, or cubic $[\mathrm{F}(2,18)$ $=.20, \mathrm{p}>.05]$ components.

An analysis of variance was employed to ascertain the effects of dietary lead acetate on the number of 
Table 1

Mean Number of Errors Across Trials for the Three Treatment Groups

\begin{tabular}{cccccrrrrrr}
\hline & \multicolumn{10}{c}{ Trial } \\
\cline { 2 - 8 } Treatment & 1 & 2 & 3 & 4 & 5 & 6 & 7 \\
\hline 50 & 3.71 & 2.48 & 1.95 & 1.75 & 1.69 & 1.20 & 1.02 & .75 \\
25 & 4.61 & 2.54 & 1.76 & 1.56 & 1.30 & 1.08 & 1.10 & .84 \\
0 & 3.40 & 1.98 & 1.34 & 1.24 & 1.34 & .80 & .82 & .52 \\
\hline
\end{tabular}

*ppm lead acetate.

squares traversed. No significant differences were found to exist as a function of dietary lead concentration, although the control animals traversed fewer squares per trial $(\bar{X}=17.54)$ than either the animals receiving $25 \mathrm{ppm}$ lead acetate $(\overline{\mathrm{X}}=19.51)$ or those receiving $50 \mathrm{ppm}$ lead acetate $(\overline{\mathrm{X}}=18.51)[\mathrm{F}(2,18)$ $=2.44, \mathrm{p}>.05]$.

The traditional measure used to evaluate performance in the Hebb-Williams closed-field maze, the number of error zones entered over the 12 problems, was computed for each subject and an analysis of variance performed. The mean number of errors in traversing the maze enclosure per trial for the groups receiving 50,25, and $0 \mathrm{ppm}$ lead acetate were $1.82,1.85$, and 1.43 , respectively $[\mathrm{F}(2,18)=3.63$, $\mathrm{p}<.05]$. Both the group receiving $50 \mathrm{ppm}$ lead acetate and the group receiving $25 \mathrm{ppm}$ lead acetate were found to have made significantly more errors than the untreated control group $[\mathrm{t}(12)=5.14, \mathrm{p}<.01$ and $\mathrm{t}(12)=2.32, \mathrm{p}<.05$, respectively]. Comparison of the group receiving $50 \mathrm{ppm}$ lead acetate with that receiving $25 \mathrm{ppm}$ lead acetate yielded no significant differences [t(12) $=.12, \mathrm{p}>.05]$. All subjects, regardless of dietary lead concentration, were found to manifest a significantly decreasing trend in the total number of errors across trials, as shown by trial means of $3.91,2.33,1.68,1.52,1.44,1.03$, .98 , and $.71[\mathrm{~F}(7,126)=155.38, \mathrm{p}<.001]$. Trend analysis confirmed significant linear $[\mathrm{F}(1,18)=$ 430.97, $\mathrm{p}<.001]$, quadratic $[\mathrm{F}(1,18)=164.73$, $\mathrm{p}<.001]$, and cubic $[\mathrm{F}(1,18)=63.17, \mathrm{p}<.001]$ components which accounted for $79.38 \%, 13.01 \%$, and $5.91 \%$ of the total variance, respectively. Although no significant differences were found between the trends of the trial means for the three treatment groups in either the linear component $[\mathrm{F}(2,18)=$ $2.63, \mathrm{p}>.05]$ or the cubic component $[\mathrm{F}(2,18)=$ $1.65, \mathrm{p}>.05]$, a significant quadratic interaction was found $[F(2,18)=10.98, p<.001]$. Table 1 presents the mean number of errors across trials for the three treatment groups.

\section{DISCUSSION}

Latency to leave the startbox to enter an open field has been considered an expression of emotionality or fear and avoidance tendencies (Zimmermann $\&$ Wells, 1971). Failure to find significant differences in the latency times suggests that postweaning treatment with lead acetate at concentrations of 50 and $25 \mathrm{ppm}$, as compared to control animals, does not elicit these behaviors. This result provides additional support for the findings of Driscoll and Stegner (1976) and Winneke et al. (1977), in which prenatal exposure to lead acetate followed by postnatal exposure did not result in significant differences in emotionality as measured by the number of boluses deposited per unit time in an open field.

The effects of dietary lead acetate produced a notable variation in maze time. Subjects receiving $50 \mathrm{ppm}$ lead acetate exhibited significantly slower times in traversing the maze enclosure as compared to control animals. The failure to find significant differences in maze time between the subjects receiving $25 \mathrm{ppm}$ lead acetate and the control animals is suggestive of a threshold of effect. That is, $25 \mathrm{ppm}$ lead acetate does not appear to be great enough to lead to significantly reduced maze times, whereas lead acetate at a concentration of $50 \mathrm{ppm}$ is. Maze time within the Hebb-Williams maze, however, is probably not a very sensitive indicator of learning. Therefore, modest learning deficits would be comparable with no differences in maze time. The fact that all subjects exhibited a decreasing time within the maze enclosure across trials may be accounted for, primarily, by intraproblem learning. That no significant interaction was found between the dietary lead conditions and trials lends support for the conclusion that similar, though not equivalent, learning curves were obtained across trials irrespective of dietary lead concentration.

With respect to the most often employed determinant of learning ability and performance in the HebbWilliams closed-field maze, the total number of errors or the total number of error zones entered over the 12 individual problems, dietary lead acetate concentrations were found to significantly affect performance. Markedly greater numbers of errors were exhibited both by subjects receiving $50 \mathrm{ppm}$ lead acetate and those receiving $25 \mathrm{ppm}$ lead acetate, as compared to control animals. No significant differences, however, were found between the subjects receiving $50 \mathrm{ppm}$ lead acetate and those receiving $25 \mathrm{ppm}$ lead acetate. In specification of the degree of intraproblem learning and the rate of learning within each problem, significant decreases in errors were exhibited by all of the subjects across trials regardless of dietary lead con- 
centration. Although similar learning curves were obtained for the three treatment groups which did not differ significantly in either the linear or cubic components, significant differences were found in the curvature of the trial means, with the control animals exhibiting the greatest degree of curvature, hence the most rapid rate of intraproblem learning.

What is evident from the data is that learning deficits can be produced in the weanling rat by postweaning lead exposure alone, although at levels similar to those which cause encephalopathy in the developing neonate (Golter \& Michaelson, 1975; Sauerhoff \& Michaelson, 1973). In both normal and lead-treated rats, excessive accumulations of lead have been observed in the area of the dentate gyrus (Danscher, Fjerdingstad, Fjerdingstad, \& Fredens, 1976; Fjerdingstad, Danscher, \& Fjerdingstad, 1974). It is possible, as Lanthorn and Isaacson (1978) have suggested, that lead accumulations in this area may preclude normal functioning of the hippocampal formation and thereby affect learning. The present results, however, must be cosidered as potentially indicating lead intoxication with concomitant elevated soft tissue body burdens concurrent with behavioral testing, and do not indicate whether the learning deficits found would persist beyond the period of lead exposure.

None of the classical symptoms of lead poisoning, such as stunted growth, tremors, or weight loss, were produced in the rat at these levels of exposure. Since lead acetate was administered in the drinking water, the possibility of introducing the confounding factors derived from intubation or injection procedures was eliminated. Early stress and trauma associated with intraperitoneal injections may cause behavioral aberrations during the later stages of development. This fact may explain the reason for the differences found in the present study as opposed to a similar investigation by Snowdon (1973) which reported no differences in the modified Hebb-Williams maze between lead-injected and control-injected weanling rats.

\section{REFERENCES}

Allen, J. R., McWey, P. J., \& Suomi, S. J. Pathological and behavioral effects of lead intoxication in the infant rhesus monkey. Environmental Health Perspectives, 1974, 7, 239-246.

Brown, D. R. Neonatal lead exposure in the rat: Decreased learning as a function of age and blood lead concentrations. Toxicology and Applied Pharmacology, 1975, 32, 628-637.

Brown, S., Dragann, N., \& Vogel, W. H. Effects of lead acetate on learning and memory in rats. Archives of Environmental Health, 1971, 22, 370-372.

Carson, T. L., VanGelder, G. A., Karas, G. G., \& Buck, W. B. Development of behavioral tests for the assessment of neurologic effects of lead in sheep. Environmental Health Perspectives, 1974, 7, 233-237. (a)

Carson, T. L., VanGelder, G. A., Karas, G. G., \& Buck, W. B. Slowed learning in lambs prenatally exposed to lead. Archives of Environmental Health, 1974, 29, 154-156. (b)

Castellino, N., \& Aloj, S. Kinetics of the distribution and excretion of lead in the rat. British Journal of Industrial Medicine, 1964, 21, 308-314.

Danscher, G., Fuerdingstad, E. J., Fuerdingstad, E., \& Fredens, K. Heavy metal content in subdivisions of the rat hippocampus (zinc, lead, copper). Brain Research, 1976, 112, 442-446.

Driscoll, J. W., \& Stegner, S. E. Behavioral effects of chronic lead ingestion on laboratory rats. Pharmacology, Biochemistry \& Behavior, 1976, 4, 411-417.

Fuerdingstad, E. J., Danscher, G., \& Fuerdingstad, E. Hippocampus: Selective concentration of lead in the normal rat brain. Brain Research, 1974, 80, 350-354.

Golte R, M., \& Michaelson, I. A. Growth, behavior, and brain catecholamines in lead exposed neonatal rats: A reappraisal. Science, 1975, 187, 359-361.

Heвb, D. O., \& Williams, K. A. A method of rating animal intelligence. Journal of Genetic Psychology, 1946, 34, 59-65.

LANThorn, T., \& IsaACSON, R. L. Effects of chronic lead ingestion in adult rats. Physiological Psychology, 1978, 6, 93-95.

Rabinovitch, M., \& Rosvold, H. A closed-field intelligence test for rats. Canadian Journal of Psychology, 1951, 5, 122-138.

Reiter, L. W., Anderson, G. E., Laskey, J. W., \& Cahill, D. F. Developmental and behavioral changes in the rat during chronic exposure to lead. Environmental Health Perspectives, $1975,12,119-123$.

Sauerhoff, M. W., \& Michaelson, I. A. Hyperactivity and brain catecholamines in lead-exposed developing rats. Science, 1973, 182, 1022-1024.

Shapiro, M. M., Tritschler, J. M., \& Ulm, R. A. Lead contamination: Chronic and acute behavioral effects in the albino rat. Bulletin of the Psychonomic Society, 1973, 2, 94-96.

Silbergeld, E. K., \& Goldberg, A. M. Lead-induced behavioral dysfunction: An animal model of hyperactivity. Experimental Neurology, 1974, 42, 146-157.

Snowdon, C. T. Learning deficits in lead-injected rats. Pharmacology, Biochemistry \& Behavior, 1973, 1, 599-603.

Sobotka, T. J., Brodie, R. E., \& Cook, M. P. Physiological effects of early lead exposure. Toxicology, 1975, 5, 175-191.

Sовотка, T. J., \& Соок, M. P. Postnatal lead acetate exposure in rats: Possible relationship to minimal brain dysfunction. American Journal of Mental Deficiency, 1974, 79, 5-9.

VanGelder, G. A., Carson, T., Smith, R. M., \& Buck, W. B. Behavioral toxicologic assessment of the neurologic effect of lead in sheep. Clinical Toxicology, 1973, 6, 405-418.

WARREN, J. The effect of telencephalic injuries on learning by paradise fish, Macropodus opercularis. Journal of Comparative and Physiological Psychology, 1961, 54, 130-132.

Warren, J. M., Warren, H. B., \& Akert, K. Learning by cats with lesions in the prestriate cortex. Journal of Comparative and Physiological Psychology, 1961, 54, 629-632.

Wells, A. M., Geist, C. R., \& ZimmermanN, R. R. Influence of environmental and nutritional factors on problem solving in the rat. Perceptual and Motor Skills, 1972, 35, 235-244.

Wilson, M., Warren, J. M., \& Abbott, L. Infantile stimulation, activity, and learning by cats. Child Development, 1965, 36, 843-853.

Winneke, G., Brockhaus, A., \& Baltissen, R. Neurobehavioral and systemic effects of longterm blood lead-elevations in rats. I. Discrimination learning and open field behavior. Archives of Toxicology, 1977, 37, 247-263.

Zimmermann, R. R. Performance of baby monkeys on the HebbWilliams closed-field maze learning task. Developmental Psychobiology, 1969, 2, 40-42.

Zimmermann, R. R., \& Wells, A. M. Performance of malnourished rats on the Hebb-Williams closed-field maze learning task. Perceptual and Motor Skills, 1971, 33, 1043-1050.

(Received for publication June 12, 1979; revision accepted November $13,1979$. 